\title{
ORIGINAL ARTICLE Healthy individuals treated with clomipramine: an fMRI study of brain activity during autobiographical recall of emotions
}

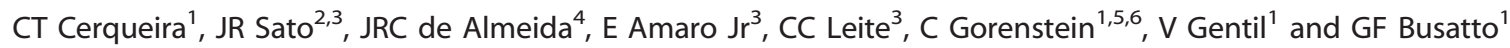

\begin{abstract}
Various functional magnetic resonance imaging studies addressed the effects of antidepressant drugs on brain functioning in healthy subjects; however, none specifically investigated positive mood changes to antidepressant drug. Sixteen subjects with no personal or family history of psychiatric disorders were selected from an ongoing 4-week open trial of small doses of clomipramine. Follow-up interviews documented clear positive treatment effects in six subjects, with reduced irritability and tension in social interactions, improved decision making, higher self-confidence and brighter mood. These subjects were then included in a placebocontrolled confirmatory trial and were scanned immediately after 4 weeks of clomipramine use and again 4 weeks after the last dose of clomipramine. The functional magnetic resonance imaging (fMRI) scans were run during emotion-eliciting stimuli. Repeated-measures analysis of variance of brain activity patterns showed significant interactions between group and treatment status during induced irritability $(P<0.005$ cluster-based) but not during happiness. Individuals displaying a positive subjective response do clomipramine had higher frontoparietal cortex activity during irritability than during happiness and neutral emotion, and higher temporo-parieto-occipital cortex activity during irritability than during happiness. We conclude that antidepressants not only induce positive mood responses but also act upon autobiographical recall of negative emotions.
\end{abstract}

Translational Psychiatry (2014) 4, e405; doi:10.1038/tp.2014.47; published online 1 July 2014

\section{INTRODUCTION}

The specific neural mechanisms whereby selective serotonin reuptake inhibitors and serotonin-norepinephrine reuptake inhibitors exert their therapeutic effects are not fully established. Recent functional magnetic resonance imaging (fMRI) studies conducted under controlled conditions assessed brain activation in healthy individuals receiving citalopram, ${ }^{1-4}$ fluvoxamine, ${ }^{5}$ reboxetine $^{6-10}$ or escitalopram ${ }^{2,11-13}$ administered in single or multiple doses for 1-3 weeks. Using a variety of emXotion-eliciting experimental paradigms, these studies provided evidence that selective serotonin reuptake inhibitors and serotonin-norepinephrine reuptake inhibitors modulate the changes in cortical and subcortical limbic activity that are typically elicited during the presentation of emotionally salient stimuli. ${ }^{14}$

It has been postulated that the efficacy of antidepressants is related to the reversal of automatic responses to emotional information and of mood-dependent negative emotional biases. ${ }^{15-18}$ Conversely, other studies reported decreased negative affects, improved cognition and increased social behaviors after use of low doses of antidepressants in a subset of healthy individuals. $^{19,20}$ However, the aforementioned fMRI studies in normals did not specify the features characterizing subgroups displaying clear improvement of mood, self-perception and performance changes in response to antidepressants. To date, $\mathrm{fMRI}$ studies of this nature have been restricted to patients who respond positively to antidepressant treatment. They have changes in a wide range of brain regions believed to be implicated in the evaluation of emotionally salient stimuli and generation of emotional states, including the following: amygdala, ventral striatum, orbitofrontal and visual cortical areas; the ventral anterior cingulate cortex and insula (involved in the central mapping of autonomic and visceral reactions associated with emotions); or areas implicated in attention, memory and regulation of emotion-triggered behaviors, including the hippocampus, dorsal anterior cingulate, and parietal and dorsolateral prefrontal cortices. $^{15,21-29}$ However, recent fMRI studies argue that such neural correlates of changes may be confounded by disease and treatment-related variables, as well as brain activity changes due to the remission of insomnia and other features of depression. . $^{15-18,24}$

In this study, we investigated brain activity differences between a group of healthy subjects without personal or family history of psychiatric disorders who showed positive mood and behavior changes in response to continued use of low doses of clomipramine, and a control group of healthy individuals who displayed no mood changes under clomipramine treatment. fMRI data during presentation of emotion-provoking stimuli under clomipramine use and after clomipramine washout were acquired for both groups, in order to check for distinct activity patterns in the brain regions relevant to emotional processing.

\section{MATERIALS AND METHODS}

Subjects

Sixteen healthy individuals ( $21-50$ years of age), right-handed according to the Edinburgh Handedness Inventory ${ }^{30}$ were selected from a larger sample included in a controlled drug trial of low doses of clomipramine in healthy

\footnotetext{
${ }^{1}$ Department and Institute of Psychiatry, School of Medicine and Hospital das Clínicas, University of São Paulo, São Paulo, Brazil; ${ }^{2}$ Department of Cognitive Neuroscience, Federal University of the ABC, Santo André, Brazil; ${ }^{3}$ Department and Institute of Radiology, School of Medicine, University of São Paulo, São Paulo, Brazil; ${ }^{4}$ Department of Psychiatry, School of Medicine, University of Pittsburgh, Pittsburgh, PA, USA; ${ }^{5}$ Laboratory of Psychopharmacology (LIM 23), School of Medicine, USP, São Paulo, Brazil and ${ }^{6}$ Department of Pharmacology, Institute of Biomedical Sciences, USP, São Paulo, Brazil. Correspondence: Dr CT Cerqueira, Department and Institute of Psychiatry, School of Medicine and Hospital das Clínicas, University of São Paulo, Rua Dr Ovídio Pires de Campos 785, São Paulo, SP 05430-010, Brazil. 


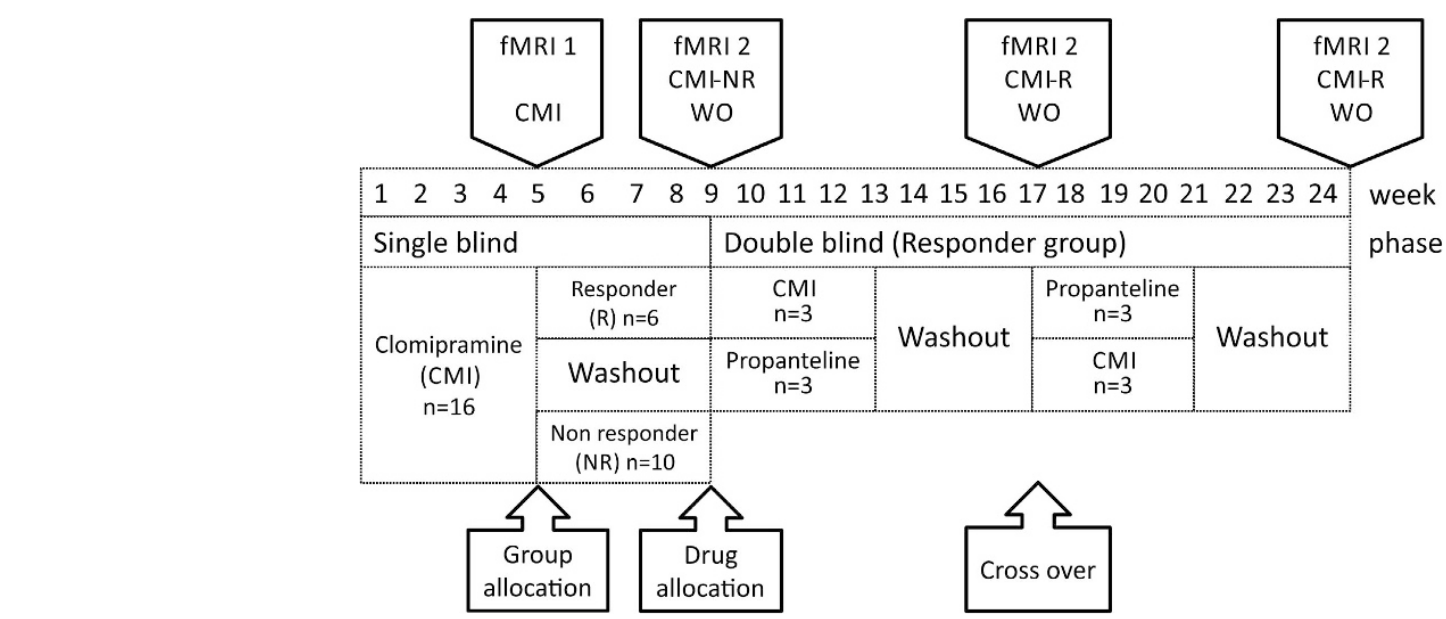

Figure 1. Timelines for each arm of the clomipramine drug trial, group allocation and sequencing of the two functional magnetic resonance imaging (fMRI) scanning sessions for the two groups (responders and non-responders to clomipramine).

subjects. ${ }^{19}$ Participants were recruited through newspaper and radio advertisements, and were screened by psychiatrists using the Structured Clinical Interview for Diagnostic and Statistical Manual of Mental Disorders. ${ }^{31}$ Subjects had no personal or first-degree family history of psychiatric disorders such as psychosis, mood disorders or drug addiction, as assessed by the Family History Screen ${ }^{32}$ and no personal history of neurological or general medical conditions, as assessed by a clinical interview, physical examination, electrocardiography, and blood and urine tests. They were not using drugs with psychotropic effects. Pregnant or lactating females in the past 6 months were excluded. The study was approved by the local ethics committees, and all participants gave written informed consent.

\section{Treatment trial}

Clomipramine was chosen for the present study because of its potency in panic disorder/agoraphobia, allowing reports of subtle mood changes that might otherwise be masked by the side-effects of higher doses of this and other antidepressant drugs. ${ }^{33}$ Accordingly, pharmacological studies using animal tissue or human cloned receptors have shown that clomipramine displays strong, dual action both as serotonin and noradrenalin reuptake inhibitor, fulfilling the criteria of an serotonin-norepinephrine reuptake inhibitor antidepressant even in greater conformity than the more recently marketed agents venlafaxine and duloxetine. ${ }^{34}$ Low doses of clomipramine, such as $10 \mathrm{mg}$, have been shown to occupy $80 \%$ of $5-\mathrm{HT}$ transporters, which is similar to the occupation pattern obtained with clinical doses of more selective 5-HT reuptake inhibitors, such as fluoxetine. ${ }^{35}$

The design of the treatment trial consisted of a first phase in which clomipramine or an active placebo was administered under single-blind conditions. The clomipramine doses were gradually increased over 2 weeks, according to tolerability up to a maximum of $40 \mathrm{mg}$ per day and maintained thereafter for an additional period of 2 weeks. Subjects underwent a weekly semi-structured interview by two experienced psychiatrists who inquired about subjective changes in emotional responses to everyday stimuli. At the end of week 4, subjects were classified as responders or non-responders on the basis of whether or not they met at least three of the following criteria: increased interpersonal tolerance (less irritability and tension in social interactions); increased mental efficiency (better decision making, improved ability to prioritize tasks and increased self-confidence); increased well-being (brighter mood); and awareness of a substantial change from their usual subjective state. These four criteria were selected on the basis of the mood and performance effects observed in healthy volunteers during a previous clomipramine trial carried out by our group. ${ }^{19}$ The semi-structured interview employed probe questions with standard wording to elucidate the changes experienced by individuals and a glossary defining each type of change. Two psychiatrists classified individuals as responders or nonresponders by consensus. All subjects completing the 4 weeks of singleblind clomipramine use (both responders and non-responders) were invited to take part in the present fMRI study. The mean dose of clomipramine was $37 \mathrm{mg}$ per day (s.d. $6.8 \mathrm{mg}$ per day) in the non- responder group and $36.7 \mathrm{mg}$ per day (s.d. $5.2 \mathrm{mg}$ per day) in the responder group. Only the responders were then included in a confirmatory double-blind cross-over trial in which they were randomized to first receive clomipramine during 4 weeks (at the same respective final doses) or placebo (propanteline, $30 \mathrm{mg}$ per day). All responders displayed a similar pattern of mood and perceived behavioral changes in the first (single-blind) and second (double-blind) phases of the clinical trial.

To decrease the risk of dropouts of clomipramine responders in this fMRI study, a fixed MRI scanning order was established: responders and nonresponders underwent a first scanning session at the end of the 4-week single-blind (first phase) of clomipramine (medicated state), and a second fMRI session after 4 weeks of clomipramine washout. The second scanning session was carried out 4 weeks after the end of the single-blind phase of clomipramine in the group of non-responders (washout). The time of the second fMRI scanning session of the responder group varied depending on whether the subject received clomipramine or propanteline as the first treatment during the confirmatory double-blind trial. Those on clomipramine first had a washout of 4 weeks, then immediately underwent the second fMRI session and subsequently entered the final phase of propanteline use. Those subjects who started the confirmatory trial using propanteline were switched after 4 weeks to clomipramine and underwent their second fMRI session after 4 weeks of clomipramine washout. Figure 1 displays the timeline of group allocation and treatment protocols. Therefore, all individuals underwent a first scanning session immediately after 4 weeks of clomipramine treatment, and a second scanning after clomipramine washout.

Table 1 shows the demographic characteristics of the two groups. All subjects in the responder group were females. The non-responder group

Table 1. Demographic details, vividness of visual imagery ratings and clomipramine doses for the two groups

\begin{tabular}{lccc}
\hline Variables & \multicolumn{3}{c}{ Groups } \\
\cline { 2 - 4 } & Responder & $\begin{array}{c}\text { Non- } \\
\text { responder }\end{array}$ & $\begin{array}{c}\text { Statistic } \\
\text { (P-value) }\end{array}$ \\
\hline $\begin{array}{l}\text { Gender, } n \\
\quad \text { Male }\end{array}$ & 0 & 3 & $2.22(0.14)$ \\
$\quad$ Female & 6 & 7 & $0.70(0.49)$ \\
Age (years), mean (s.d.) & $30.7(14.8)$ & $34.7(6.5)$ & \\
Years of education, mean & $11.3(0.8)$ & $11.6(1.2)$ & $-0.53(0.60)$ \\
$\begin{array}{l}\text { (s.d.) } \\
\text { VVIQ }{ }^{\text {b }} \text { mean (s.d.) }\end{array}$ & $34.3(11.8)$ & $34.2(10.3)$ & $0.02(0.98)$ \\
Clomipramine dose (mg & $36.67(5.16)$ & $37(6.75)$ & $-0.11(0.91)$ \\
per day), mean (s.d.) & & & \\
\hline a $X^{2}$ for categorical variables; $t$-test for continuous variables. ${ }^{b}$ Vividness of \\
Visual Imagery Questionnaire.
\end{tabular}


had three males and seven females. There were no other significant differences between groups (Table 1).

\section{Experimental paradigm}

A previously validated interview was applied 2 weeks before the first fMRI session to select emotionally salient autobiographical experiences occurring over the past 6 months. ${ }^{25,26}$ Subjects completed the Vividness of Visual Imagery Questionnaire ${ }^{36}$ during this interview. There was no between-group difference in the Vividness of Visual Imagery Questionnaire scores (Table 1).

Within 5 days before the first fMRI session, subjects were trained and adapted to the fMRI procedure in a sham session, in a mock scanner reproducing the MRI environment and the sounds emitted during image acquisition.

During the fMRI session, subjects listened to recordings through nonmagnetized headsets (Commander-XG; Resonance Technology, Los Angeles, CA, USA). Three separate runs were performed, each consisting of an initial baseline period of rest $(80 \mathrm{~s})$ followed by three emotioneliciting trials (happiness, neutral emotion and irritability). Each trial consisted of the presentation of one non-personal text $(20 \mathrm{~s})$ and one personal script of specific emotional state induction $(60 \mathrm{~s})$. In view of the possible confounding effects, the order of the happiness and irritability trials was alternated, both within and between subjects, although the neutral emotion trial was always performed between the other two. Immediately after the presentation of each personal script or baseline rest period, a self-report assessment was performed using four-point visual scales of happiness, irritability or anxiety (applied in pseudo-randomized order). The visual scales were presented via a mirror mounted on the head coil of the fMRI scanner. To determine the levels of anxiety across the overall scanning procedure, the state form of the State-Trait Anxiety Inventory $(\mathrm{STAI}-\mathrm{S})^{37}$ was applied immediately before and after image acquisition.

\section{Behavioral data analysis}

For each of the three visually rated emotions (irritability, happiness and anxiety), repeated-measures analyses of variance (ANOVAs) checked for significant interactions between group (responders versus non-responders) and treatment status (medicated versus unmedicated); this was used to verify whether the responder group displayed lesser negative emotional reactions during $\mathrm{fMRI}$ scanning (as assessed by lower irritability and anxiety ratings) and greater positive responses (as assessed by higher happiness rating scores) compared with non-responders. For these ANOVAs, the scores for each visual rating scale of emotions (happiness, irritability and anxiety) during the irritability, and happiness-provoking trials were subtracted from the corresponding scores during the neutral scripts' trial. Therefore, the average ratings for each of those three visually rated emotions were expressed as the difference between the scores obtained during the emotion-provoking situations and the neutral situation, that is, irritability minus neutral $(\mathrm{I}-\mathrm{N})$ and happiness minus neutral $(\mathrm{H}-\mathrm{N})$ visual rating scores. Such normalization of scores to the neutral condition was intended to decrease intersubject variability of emotional ratings. $t$-tests were performed for the post hoc evaluation of any statistically significant interactions. ANOVA was also used to compare pre- and post-fMRI scanning STAI-S scores.

\section{Image acquisition}

For each fMRI run, 220 gradient-echo $\mathrm{T}^{*}$-weighted echo-planar imaging sets were obtained using a GE LX-MR 1.5T scanner (General Electric, Milwaukee, WI, USA). Each set consisted of 15 interleaved non-contiguous 7.0-mm-thick transaxial slices, with $0.7-\mathrm{mm}$ gap, parallel to the intercommisural line. Imaging parameters were as follows: echo time $=40 \mathrm{~ms}$; repetition time $=2 \mathrm{~s}$; matrix $64 \times 64$; interslice gap $=0.3 \mathrm{~mm}$; field-ofview $=200 \times 200 \mathrm{~mm}$; and flip angle $=90^{\circ}$. Stimulus presentation was synchronized with image acquisition via an optical relay, triggered by the radiofrequency pulse. A purpose-written software was used for synchronizing the presentation of stimuli and visual analog scales, as well as the capture of subject responses and image acquisition.

\section{fMRI data analysis}

Image processing involved, first, data realignment and spin history correction to minimize motion-related artifacts ${ }^{38}$ and spatial Gaussian smoothing (full width at half-maximum $=7.2 \mathrm{~mm}$ ). The modeling of the blood oxygen level-dependent (BOLD) response curve was carried out by using a linear combination of two Poisson functions with peaks at 4 and $8 \mathrm{~s}$ after the onset. The goodness of fit statistic was computed at each voxel ${ }^{35}$ by the residual sum of squares ratio between the constrained (null) model (assuming the respective beta coefficients as zero) and the full model. The sum of square ratio distribution under the null hypothesis was obtained by permutations of the time-series using wavelet-based re-sampling as previously described. ${ }^{39}$ This permutation method has been shown to provide good type I error control with minimal distributional assumptions.

The sum of square ratio maps were registered into standard space by rigid body transformation of the fMRI data into structural images obtained for the same subjects, followed by affine transformations onto a template. ${ }^{40}$ In the individual analysis within each fMRI run, the sum of square ratio map for the irritability provoking trial was subtracted from the map for the neutral trial and happiness-provoking trial. Likewise, the map for the happiness trial was subtracted from the map for neutral trial. Therefore, the average maps of the three runs were expressed as irritability minus neutral $(\mathrm{I}-\mathrm{N})$, irritability minus happiness $(\mathrm{I}-\mathrm{H})$ and happiness minus neutral $(\mathrm{H}-\mathrm{N})$ contrasts. The average contrast maps across the three runs were subsequently used in the group comparisons. For each contrast $(\mathrm{I}-\mathrm{N}, \mathrm{I}-\mathrm{H}$ and $\mathrm{H}-\mathrm{N})$, in order to identify voxel clusters showing significant BOLD response differences between groups, a two-way ANOVA was carried out searching for significant interactions between group (responders versus non-responders) and treatment status (medicated versus unmedicated). Statistical significance was assessed nonparametrically by permutations, considering voxel and cluster type I errors of 0.05 and 0.005 , respectively.

Finally, with the aim of facilitating the interpretation of the direction of brain activity differences detected by the above ANOVA interactions, we also conducted within-group analyses investigating BOLD signal differences between the unmedicated and medicated states in each of the two groups separately, using one-way ANOVA (see the Supplementary

Table 2. Self-report visual analog scale scores for the emotional states induced during the medicated and post-washout phases

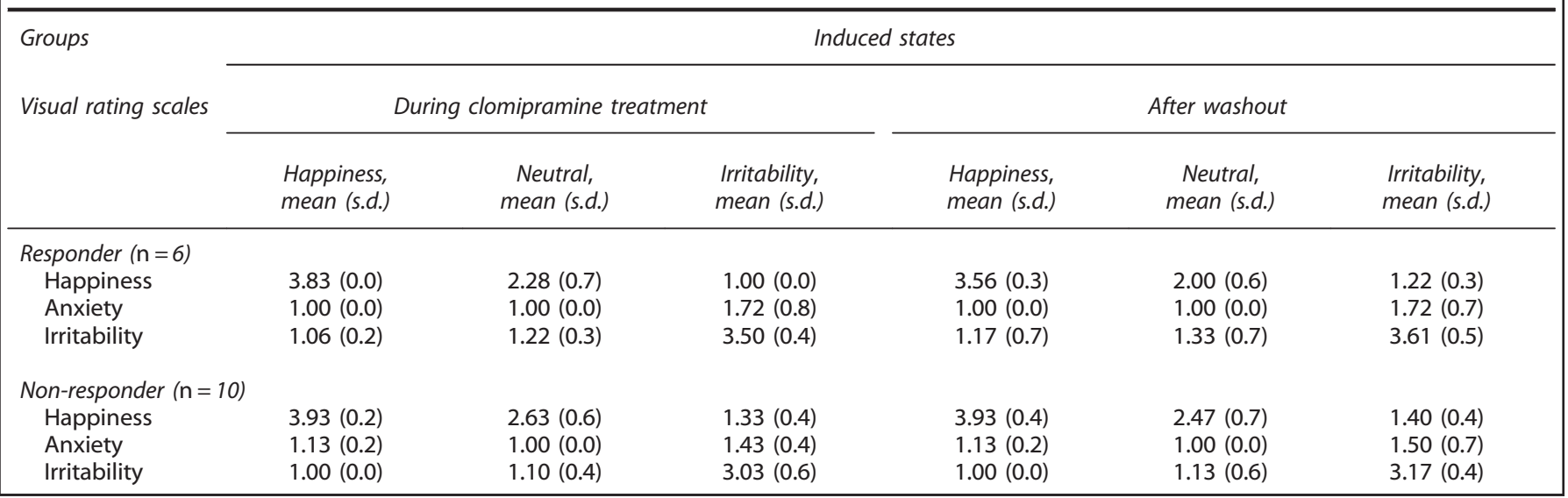


Material). In these analyses, statistical significance was assessed considering a flexible threshold of 0.05 for both voxel and cluster type I errors.

\section{RESULTS}

Behavioral data

Anxiety during scanning sessions. There was no significant difference between the pre- and post-fMRI scores on the STAI-S in the responder group $(P=0.23)$ or in the non-responder group $(P=0.09)$.

Subjective state ratings. The mean subjective self-rating scores for each emotion-eliciting condition during the medicated and unmedicated states in the two groups are provided in Table 2. During the medicated and the non-medicated phases, the highest happiness scores were recorded during the presentation of happiness scripts both by responders and non-responders, whereas the highest irritability scores were recorded during irritability-provoking scripts (all mean scores higher than 3; Table 2). This suggests that both groups were engaged in responding to the paradigm.

Scores for anxiety were low (less than 2) but were systematically higher during the induction of irritability than for the happiness and neutral conditions (Table 2). There was no significant group effects or group by treatment interaction in the ANOVAs assessing differences in scale scores across the two emotion-eliciting (irritability or happiness) conditions. This suggests absence of significant differences between responders and non-responders in regard to emotional responses upon presentation of emotionprovoking personal scripts during the fMRI scanning sessions.

\section{fMRI results}

There was a significant interaction between clomipramine and group effects in the $\mathrm{I}-\mathrm{N}$ and $\mathrm{I}-\mathrm{H}$ contrasts (Table 3 ). In the I- N contrast, there was a large cluster of stronger BOLD signal change in responders (compared with non-responders), which encompassed: the posterior portions of the superior and middle frontal gyri (Brodmann's area (BA) 8, 9); the pre- and post-central gyri (BA

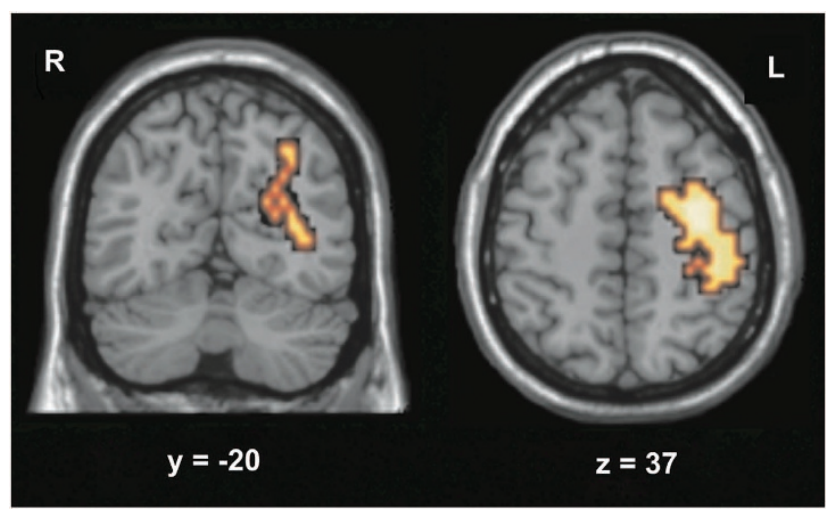

Figure 2. The areas highlighted in yellow and red represent blood oxygen level-dependent signal interaction of medication and group effects for the difference of irritability and happiness emotional states, located in the left temporo-parieto-occipital cortex (coronal view, on the left) and in the left frontoparietal cortex (axial view, on the right), and their respective Talairach-Tournoux Atlas coordinates (radiological convention).

2-4, 6); and the inferior parietal gyrus (BA 40; Figure 2). Responders also showed stronger BOLD signal change in the $\mathrm{I}-\mathrm{H}$ contrast in a cluster involving the medial frontal gyrus (BA 6), the pre- and post-central gyri (BA 2-4) and the supramarginal gyrus (BA 40), as well as in a cluster encompassing the inferior parietal and angular gyri (BA 37, 39-41), the superior and middle occipital gyri (BA 19) and the middle temporal gyrus (BA 21; Figure 2). There was no significant interaction effect for the $\mathrm{H}-\mathrm{N}$ contrast.

The spatial maps resulting from the within-group analyses (for the $\mathrm{I}-\mathrm{N}, \mathrm{I}-\mathrm{H}$ and $\mathrm{H}-\mathrm{N}$ contrasts, respectively) are shown in the Supplementary Material. These maps display brain regions of significantly increased or decreased BOLD signal during the medicated versus unmedicated state separately for the responder

Table 3. Local maxima and extent of clusters with blood oxygen level-dependent signal interaction of group and treatment effects on emotional states differences

\begin{tabular}{|c|c|c|c|c|c|c|}
\hline \multirow{2}{*}{$\begin{array}{l}\text { Emotional states subtraction } \\
\text { Relationship }\end{array}$} & \multirow[t]{3}{*}{ Brodmann's area } & \multirow[t]{3}{*}{$K$ (voxels) } & \multicolumn{3}{|c|}{ Talairach coordinates } & \multirow[t]{3}{*}{ Cluster $\mathrm{P}$} \\
\hline & & & \multirow{2}{*}{$(\mathrm{x})$} & \multirow{2}{*}{ (y) } & \multirow{2}{*}{ (z) } & \\
\hline Brain region & & & & & & \\
\hline \multicolumn{7}{|l|}{ Irritability-neutral } \\
\hline \multicolumn{7}{|l|}{ Responder $>$ non-responder } \\
\hline Superior and middle frontal gyri & $6,8,9$ & 79 & -43 & -18 & 37 & 0.002 \\
\hline \multicolumn{7}{|l|}{ Responder $<$ non-responder } \\
\hline \multicolumn{7}{|l|}{ None } \\
\hline \multicolumn{7}{|l|}{ Irritability_happiness } \\
\hline \multicolumn{7}{|l|}{ Responder $>$ non-responder } \\
\hline Superior and middle occipital gyri & 19 & 88 & -26 & -67 & 9 & 0.003 \\
\hline Inferior parietal and angular gyri & $37,39,40,41$ & & & & & \\
\hline \multicolumn{7}{|l|}{ Responder $<$ non-responder } \\
\hline \multicolumn{7}{|l|}{ None } \\
\hline Happiness-neutral & & & & & & \\
\hline None & & & & & & \\
\hline
\end{tabular}


group (Supplementary Table S1) and the non-responder group (Supplementary Table S2).

\section{DISCUSSION}

To our knowledge, this is the first fMRI study evaluating healthy individuals who reported consistent changes in mood and emotional behavior after chronic use of an antidepressant. When presented with irritability-inducing stimuli while under clomipramine treatment, responders showed a pattern of brain activity that was significantly different from that of the non-responders under the same conditions. Among the non-responders, taskrelated BOLD signal changes during presentation of emotionprovoking autobiographical scripts were lower in the medicated state than after washout, whereas the responders showed higher frontoparietal activity during the induction of irritability when medicated than after washout.

Similarly to these findings $\mathrm{FMRI}$ studies using emotion-eliciting stimuli in patients with mood disorders under antidepressant treatment found clinical response to be associated with increased regional brain activity in prefrontal-parietal and other brain regions. ${ }^{15,17,27,41-50}$ Together, this suggests that stronger prefrontal-parietal BOLD signal change during emotion induction is a neural correlate of antidepressant drug effects on mood regulation. However, this effect may be independent of the therapeutic action of antidepressants, as this and other studies show that such pattern also occurs in healthy individuals. ${ }^{8-10,12,51,52}$

The absence of differences in clomipramine doses and plasma levels, as well as in the suppression of REM sleep (unpublished data on file) between the responder and non-responder groups in this study, indicates that the brain activity changes in the treatment-responders were not because of pharmacokinetic factors but may result from genetic variations in mood regulation in an extratherapeutic response to these drugs. ${ }^{53,54}$ In this vein, it is noteworthy that previous studies of antidepressant response in clinical samples have implicated gene variations unrelated to vulnerability to mood disorders. ${ }^{55}$ The differences in brain activity between responders and non-responders were localized to leftlateralized brain clusters primarily involving the frontal and parietal cortices. This suggests that the neural substrate specifically associated with the response to clomipramine in healthy subjects does not involve the more extensive, multifocal cortical-subcortical circuitry that is typically engaged during nonpersonal emotional tasks. However, the small size of our sample may have precluded the detection of less salient (but still potentially relevant) BOLD signal differences in other brain regions involved in emotional processing.

The brain regions in which the BOLD signal differed between responders and non-responders are considered highly relevant for self-referential emotional tasks. ${ }^{24-29,56-58}$ As these findings are not confounded by therapeutic effects, they underscore the relevance of frontoparietal regions to emotional processing and to the psychopharmacological effects of clomipramine. The magnitude of the differences in activity between groups in the frontoparietal region may have been influenced by the choice of a paradigm of autobiographic recall to elicit emotional responses, ${ }^{25,26}$ and further studies using other emotion-eliciting paradigms are warranted.

Moreover, noteworthy is the finding of brain activity differences between responder and non-responder groups during the emotional condition of negative valence (irritability), rather than during the happiness condition. Previous fMRI studies of healthy individuals reported higher frontoparietal activity during recollection of self-relevant negative information than during retrieval of self-relevant positive information. ${ }^{6,8}$ The valence-specific findings of the present study are consistent with previous observations that healthy individuals who report beneficial effects from treatment with antidepressants fell less responsive to negative emotional experiences, rather than being more prone to positive experiences. $^{20}$

Inspection of the mean subjective self-rating scores showed an overall pattern of higher negative emotion scores (irritability and anxiety) during presentation of irritability scripts and higher positive emotion scores (happiness ratings) during presentation of happiness scripts. This indicates that subjects responded emotionally to the paradigm during both conditions. The lack of significant differences between responders and non-responders in emotional response under emotion-provoking personal scripts during $f M R I$ scanning suggests that the visual scales were not sensitive enough to discriminate, during the fMRI sessions, the daily life emotional changes reported during treatment by the responders to clomipramine. Likewise, a decoupling between subjective emotional responses and the objective BOLD signal changes elicited during experimental situations has been reported in a number of previous fMRI studies that used emotion-provoking tasks in healthy individuals. $2,4,7,8,11,59,60$

The results of the within-group brain activity comparisons in the non-responder group (see Supplementary Information, Supplementary Table S2), with treatment-related BOLD signal reductions in brain regions considered critical to emotional processing, are similar to those reported during emotional stimuli in previous fMRI studies of healthy individuals treated with multiple doses of antidepressants. ${ }^{2,7,14,18}$ As only one-third of healthy subjects typically experience notable mood and performance changes under treatment with antidepressants, ${ }^{19,61}$ it is possible that the majority of individuals taking part in the quoted fMRI studies had effects akin to those of the non-responders in the current experiment.

Among the limitations of this study, the small sample, not balanced in gender distribution in the clomipramine responder group, may have prevented the detection of less salient but significant differences in additional brain regions relevant to emotional processing. Therefore, confirmation of the findings here reported is warranted. In addition, there was an imbalance between responders and non-responders in terms of the interval between the first and the second fMRI sessions, and in the total duration of exposure to clomipramine before the second fMRI scanning session (responders received two 4-week courses of clomipramine before their second fMRI scanning session, whereas non-responders only received a single 4-week course, as they were not included in the second phase of the trial). However, this is unlikely to have confounded the fMRI findings, as all subjects were first scanned at the end of 4 weeks of treatment with clomipramine, whereas the second scanning session was carried out after 4 weeks of washout in all cases. Finally, possible differences in nonspecific practice effects from the first to the second fMRI session (medicated versus unmedicated state) were likely minimized by the training session carried out before the first fMRI session.

In conclusion, carefully selected healthy subjects experiencing a consistent positive change in mood and perceived performance after 4 weeks of small, sub-therapeutic doses of clomipramine treatment, presented a distinct pattern of increased activity in frontoparietal regions during emotion-eliciting stimuli in comparison with non-responders. These findings underscore the need for a systematic evaluation of subjective mood changes in pharmacological fMRI studies of antidepressants in healthy subjects in order to reduce intersubject variability in brain activity patterns, and provide further evidence of specific pharmacodynamic basis for the observed differences in mood response in clinical and nonclinical samples.

\section{CONFLICT OF INTEREST}

The authors declare no conflict of interest. 


\section{ACKNOWLEDGMENTS}

This study was supported by a grant from the Fundação de Amparo à Pesquisa do Estado de São Paulo (FAPESP, São Paulo Research Foundation; Grant no. 01/00189-9).

\section{REFERENCES}

1 Murphy SE, Norbury R, O'Sullivan U, Cowen PJ, Harmer CJ. Effect of a single dose of citalopram on amygdala response to emotional faces. Br J Psychiatry 2009; 194: $5-40$.

2 Simmons AN, Arce E, Lovero KL, Stein MB, Paulus MP. Subchronic SSRI administration reduces insula response during affective anticipation in healthy volunteers. Int J Neuropsychopharmacol 2009; 12: 1009-1020.

3 Windischberger C, Lanzenberger R, Holik A, Spindelegger C, Stein P, Moser U et al. Area-specific modulation of neural activation comparing escitalopram and citalopram revealed by pharmaco-fMRI: a randomized cross-over study. Neuroimage 2010; 49: 1161-1170.

4 McCabe C, Mishor Z. Antidepressant medications reduce subcortical--cortical resting-state functional connectivity in healthy volunteers. Neuroimage 2011; 57 1317-1323.

5 Takahashi H, Yahata N, Koeda M, Takano A, Asai K, Suhara T et al. Effects of dopaminergic and serotonergic manipulation on emotional processing: a pharmacological fMRI study. Neuroimage 2005; 27: 991-1001.

6 Miskowiak K, Papadatou-Pastou M, Cowen PJ, Goodwin GM, Norbury R, Harmer $\mathrm{CJ}$. Single dose antidepressant administration modulates the neural processing of self-referent personality trait words. Neuroimage 2007; 37: 904-911.

7 Norbury R, Mackay CE, Cowen PJ, Goodwin GM, Harmer CJ. Short-term antidepressant treatment and facial processing. Functional magnetic resonance imaging study. Br J Psychiatry 2007; 190: 531-532.

8 Norbury R, Mackay CE, Cowen PJ, Goodwin GM, Harmer CJ. The effects of reboxetine on emotional processing in healthy volunteers: an fMRI study. $\mathrm{Mol}$ Psychiatry 2008; 13: 1011-1020.

9 Onur OA, Walter H, Schlaepfer TE, Rehme AK, Schmidt C, Keysers C et al. Noradrenergic enhancement of amygdala responses to fear. Soc Cogn Affect Neurosci 2009; 4: 119-126.

10 Brühl AB, Jäncke L, Herwig U. Differential modulation of emotion processing brain regions by noradrenergic and serotonergic antidepressants. Psychopharmacology (Berl) 2011; 216: 389-399.

11 Norbury R, Taylor MJ, Selvaraj S, Murphy SE, Harmer CJ, Cowen PJ. Short-term antidepressant treatment modulates amygdala response to happy faces. Psychopharmacology (Berl) 2009; 206: 197-204.

12 Brühl AB, Kaffenberger T, Herwig U. Serotonergic and noradrenergic modulation of emotion processing by single dose antidepressants. Neuropsychopharmacology 2010; 35: 521-533.

13 Matthews SC, Simmons AN, Strigo IA, Arce E, Stein MB, Paulus MP. Escitalopram attenuates posterior cingulate activity during self-evaluation in healthy volunteers. Psychiatry Res 2010; 182: 81-87.

14 Anderson IM, McKie S, Elliott R, Williams SR, Deakin JF. Assessing human 5-HT function in vivo with pharmaco-MRI. Neuropharmacology 2008; 55: 1029-1037.

15 Fitzgerald PB, Laird AR, Maller J, Daskalakis ZJ. A meta-analytic study of changes in brain activation in depression. Hum Brain Mapp 2008; 29: 683-695.

16 Van Wingen GA, Van Eijndhoven P, Cremers HR, Tendolkar I, Verkes RJ, Buitelaar JK et al. Neural state and trait bases of mood-incongruent memory formation and retrieval in first-episode major depression. J Psychiatr Res 2010; 44: 527-534.

17 Davidson RJ, Irwin W, Anderle MJ, Kalin NH. The neural substrates of affective processing in depressed patients treated with venlafaxine. Am J Psychiatry 2003; 160: 64-75.

18 Harmer CJ, Goodwin GM, Cowen PJ. Why do antidepressants take so long to work? A cognitive neuropsychological model of antidepressant drug action. $\mathrm{Br} \mathrm{J}$ Psychiatry 2009; 195: 102-108.

19 Gentil V, Zilberman ML, Lobo D, Henna E, Moreno RA, Gorenstein C. Clomipramine-induced mood and perceived performance changes in selected healthy individuals [letter]. J Clin Psychopharmacol 2007; 27: 314-315.

20 Serretti A, Calati R, Goracci A, Di Simplicio M, Castrogiovanni P, De Ronchi D. Antidepressants in healthy subjects: what are the psychotropic/psychological effects? Eur Neuropsychopharmacol 2010; 20: 433-453.

21 Mayberg HS, Brannan SK, Tekell JL, Silva JA, Mahurin RK, McGinnis S et al. Regional metabolic effects of fluoxetine in major depression: serial changes and relationship to clinical response. Biol Psychiatry 2000; 48: 830-843.

$22 \mathrm{Fu}$ CHY, Williams SCR, Brammer MJ, Suckling J, Kim J, Cleare AJ et al. Neural responses to happy facial expressions in major depression following antidepressant treatment. Am J Psychiatry 2007; 164: 599-607.

23 Drevets WC. Translating progress in depression research to the clinic: one step at a time on a very long road. World Psychiatry 2010; 9: 162.
24 Simplicio D. Short-term antidepressant administration reduces negative selfreferential processing in the medial prefrontal cortex in subjects at risk for depression. Mol Psychiatry 2011; 17: 503-510.

25 Cerqueira CT, Almeida JRC, Gorenstein C, Gentil V, Leite CC, Sato JR et al. Engagement of multifocal neural circuits during recall of autobiographical happy events. Braz J Med Biol Res 2008; 41: 1076-1085.

26 Cerqueira CT, Almeida JR, Sato JR, Gorenstein C, Gentil V, Leite CC et al. Cognitive control associated with irritability induction: an autobiographical recall fMRI study. Rev Bras Psiquiatr 2010; 32: 109-118.

27 Price JL, Drevets WC. Neurocircuitry of mood disorders. Neuropsychopharmacology 2009; 35: 192-216.

28 Young KD, Erickson K, Nugent AC, Fromm SJ, Mallinger AG, Furey ML et al. Functional anatomy of autobiographical memory recall deficits in depression. Psychol Med 2011; 29: 1-13.

29 Lemogne C, Delaveau P, Freton M, Guionnet S, Fossati P. Medial prefrontal cortex and the self in major depression. J Affect Disord 2012; 136: e1-e11.

30 Oldfield RC. The assessment and analysis of handedness: the Edinburgh inventory. Neuropsychologia 1971; 9: 97-113.

31 First MB, Spitzer RL, Gibbon M, Willians JBW. Structured Clinical Interview for DSMIV Axis I Disorders (SCID version 2.0). Biometric research Department, New York State Psychiatric Institute: New York, USA, 1995.

32 Weissman MM, Wickramaratne $\mathrm{P}$, Adams $\mathrm{P}$, Wolk S, Verdeli H, Olfson M. Brief screening for family psychiatric history: the family history screen. Arch Gen Psychiatry 2000; 57: 675-682.

33 Gentil V, Lotufo-Neto F, Andrade L, Cordás T, Bernik M, Ramos R et al. Clomipramine, a betterreferencedrug for panic/agoraphobia. I. Effectiveness comparison with imipramine. J Psychopharmacol. 1993; 7: 316-324.

34 Gillman PK. Tricyclic antidepressant pharmacology and therapeutic drug interactions updated. Br J Pharmacol 2007; 151: 737-748.

35 Wong DF, Tauscher J, Grunder G. The role of imaging in proof of concept for CNS drug discovery and development. Neuropsychopharmacology 2009; 34: 187-203.

36 Campos A, Gonzalez MA, Amor A. The Spanish version of the Vividness of Visual Imagery Questionnaire: factor structure and internal consistency reliability. Psychol Rep 2002; 90: 503-506.

37 Spielberger CD, Gorsuch RL, Lushene PR, Vagg PR, Jacobs GA. Manual for the State-Trait Anxiety Inventory. Consulting Psychologists Press: Palo Alto, CA, 1983.

38 Bullmore E, Fadili J, Breakspear M, Salvador R, Suckling J, Brammer M. Wavelets and statistical analysis of functional magnetic resonance images of the human brain. Stat Methods Med Res 2003; 12: 375-399.

39 Friman O, Borga M, Lundberg P, Knutsson H. Adaptive analysis of fMRI data. Neuroimage 2003; 19: 837-845.

40 Bullmore E, Brammer M, Williams SC, Rabe-Hesketh S, Janot N, David A et al. Statistical methods of estimation and inference for functional MR image analysis. Magn Reson Med 1996; 35: 261-277.

41 Roy M, Harvey PO, Berlim MT, Mamdani F, Beaulieu MM, Turecki G et al. Medial prefrontal cortex activity during memory encoding of pictures and its relation to symptomatic improvement after citalopram treatment in patients with major depression. J Psychiatry Neurosci 2010; 35: 152-162.

42 López-Solà M, Pujol J, Hernández-Ribas R, Harrison BJ, Contreras-Rodríguez O, Soriano-Mas $C$ et al. Effects of duloxetine treatment on brain response to painful stimulation in major depressive disorder. Neuropsychopharmacology 2010; 35 2305-2317.

43 Kennedy SH, Evans KR, Kruger S, Mayberg HS, Meyer JH, McCann S et al. Changes in regional brain glucose metabolism measured with positron emission tomography after paroxetine treatment of major depression. Am J Psychiatry 2001; 158: 899-905.

44 Canli T, Cooney RE, Goldin P, Shah M, Sivers H, Thomason ME et al. Amygdala reactivity to emotional faces predicts improvement in major depression. Neuroreport 2005; 16: 1267-1270.

45 Anand A, Li Y, Wang Y, Wu J, Gao S, Bukhari L et al. Antidepressant effect on connectivity of the mood-regulating circuit: an FMRI study. Neuropsychopharmacology 2005; 30: 1334-1344.

46 Anand A, Li Y, Wang Y, Gardner K, Lowe MJ. Reciprocal effects of antidepressant treatment on activity and connectivity of the mood regulating circuit: an FMRI study. J Neuropsychiatry Clin Neurosci 2007; 19: 274-282.

47 Moses-Kolko EL, Perlman SB, Wisner KL, James J, Saul AT, Phillips ML. Abnormally reduced dorsomedial prefrontal cortical activity and effective connectivity with amygdala in response to negative emotional faces in postpartum depression. $\mathrm{Am}$ J Psychiatry 2010; 167: 1373-1380.

48 Lemogne C, Mayberg H, Bergouignan L, Volle E, Delaveau P, Lehericy S et al. Selfreferential processing and the prefrontal cortex over the course of depression: a pilot study. J Affect Disord 2010; 124: 196-201.

49 Fales CL, Barch DM, Rundle MM, Mintun MA, Mathews J, Snyder AZ et al. Antidepressant treatment normalizes hypoactivity in dorsolateral prefrontal cortex 
during emotional interference processing in major depression. J Affect Disord 2009; 112: 206-211.

50 Hsu DT, Langenecker SA, Kennedy SE, Zubieta JK, Heitzeg MM. fMRI BOLD responses to negative stimuli in the prefrontal cortex are dependent on levels of recent negative life stress in major depressive disorder. Psychiatry Res 2010; 183: 202-208.

51 Grefkes C, Wang LE, Eickhoff SB, Fink GR. Noradrenergic modulation of cortical networks engaged in visuomotor processing. Cereb Cortex 2010; 20: 783-797.

52 Völlm B, Richardson P, McKie S, Elliott R, Deakin JF, Anderson IM. Serotonergic modulation of neuronal responses to behavioural inhibition and reinforcing stimuli: an fMRI study in healthy volunteers. Eur J Neurosci 2006; 23: 552-560.

53 Fortier E, Noreau A, Lepore F, Boivin M, Perusse D, Rouleau GA et al. Early impact of 5 -HTTLPR polymorphism on the neural correlates of sadness. Neurosci Lett 2010; 485: 261-265.

54 Pezawas L, Meyer-Lindenberg A, Drabant EM, Verchinski BA, Munoz KE, Kolachana BS et al. 5-HTTLPR polymorphism impacts human cingulate-amygdala interactions: a genetic susceptibility mechanism for depression. Nat Neurosci 2005; 8 : 828-834.

55 Savitz JB, Drevets WC. Imaging phenotypes of major depressive disorder: genetic correlates. Neuroscience 2009; 164: 300-330.

56 Knutson B, Wolkowitz OM, Cole SW, Chan T, Moore EA, Johnson RC et al. Selective alteration of personality and social behavior by serotonergic intervention. $\mathrm{Am} \mathrm{J}$ Psychiatry 1998; 155: 373-379.
57 Lemogne C, Bergouignan L, Boni C, Gorwood P, Pelissolo A, Fossati P. Genetics and personality affect visual perspective in autobiographical memory. Conscious Cogn 2009; 18: 823-830.

58 Tang TZ, DeRubeis RJ, Hollon SD, Amsterdam J, Shelton R, Schalet B. Personality change during depression treatment: a placebo-controlled trial. Arch Gen Psychiatry 2009; 66: 1322-1330.

59 Anderson IM, McKie S, Elliott R, Williams SR, Deakin JF. Assessing human 5-HT function in vivo with pharmacoMRI. Neuropharmacology 2008; 55: 1029-1037.

60 de Almeida JR, Phillips ML, Cerqueira CT, Zilberman M, Lobo D, Henna E et al. Neural activity changes to emotional stimuli in healthy individuals under chronic use of clomipramine. J Psychopharmacol 2009; 24: 1165-1174.

61 Dumont G, De Visser SJ, Cohen AF, Van Gerven J. Biomarkers for the effects of selective serotonin reuptake inhibitors (SSRIs) in healthy subjects. $\mathrm{Br} J$ Clin Pharmacol. 2005; 59: 495-510.

(c) (i) $€$ This work is licensed under a Creative Commons AttributionNonCommercial-NoDerivs 3.0 Unported License. The images or other third party material in this article are included in the article's Creative Commons license, unless indicated otherwise in the credit line; if the material is not included under the Creative Commons license, users will need to obtain permission from the license holder to reproduce the material. To view a copy of this license, visit http://creativecommons.org/licenses/by-nc-nd/3.0/

Supplementary Information accompanies the paper on the Translational Psychiatry website (http://www.nature.com/tp) 